\title{
Pattern of Abortion Care in a Tertiary Level Maternity Hospital in Nepal
}

\author{
Punya Paudel, ${ }^{1}$ Luna Paudel, ${ }^{2}$ Manisha Bhochhibhoya, ${ }^{3}$ Sapana Amatya Vaidhya, ${ }^{1}$ Nabina Shah, ${ }^{4}$ Dipendra \\ Khatiwada $^{5}$
}

${ }^{1}$ Maternity Hospital, Kathmandu, ${ }^{2}$ B.P.Koirala Institute of Health Sciences, Dharan, ${ }^{3}$ Alka Hospital, Kathmandu, ${ }^{4}$ Discipline of Public Health, Flinders University, Adelaide, Australia, ${ }^{5}$ xenoMED Foundation, Kathmandu, Nepal.

\section{ABSTRACT}

Introduction: Complications from unsafe abortion are believed to account for the largest proportion of hospital admissions for gynaecological services in developing countries and not to mention the cost it imparts to the health system of a country. Therefore, it is equally important to find out the prevalence and the pattern of abortion among the women who utilize the safe abortion care services and provide a framework to target various health promotion programs including safe-motherhood and reproductive health; such that the future interventions to avoid the unintended pregnancy and unsafe abortion can be implemented accordingly.

Methods: A cross-sectional study was conducted in a tertiary care hospital in Kathmandu, Nepal. Social and demographic information of all the women seeking induced abortions from January 2011 to December 2012 were included and the result was analyzed.

Result: Abortion contributed to about $1.68 \%$ of the total patient served in the hospital that provides both obstetrical and gynecological services. Of the total 4830 patients who underwent induced abortion in this period, the mean age was $27,92.3 \%$ were from the Kathmandu valley and more than one-third women (35.2\%) were illiterate who couldn't read and write. Majorities were more than two parity and belonged to higher caste.

Conclusion: The socio-demographic profile of the abortion clients in Nepal has remained similar over the years. We need to address the accessibility and availability to the safe abortion care services along with other safe motherhood programs guaranteeing access to safe abortion and post-abortion care to all group of women and also, women education regarding contraception to avoid repeated abortions or unwanted pregnancy in the future.

Keywords: abortion; pattern; socio-demographic.

\section{INTRODUCTION}

Of the estimated 211 million pregnancies that occur each year, total 46 million end in abortion. ${ }^{1}$ Unsafe abortion has been stated to contribute to one in eight pregnancy-related deaths attributing to a worldwide estimate of $13 \%$ of all maternal mortality ${ }^{2}$ and total loss of 4.5 million disability adjusted life years considering maternal illness. ${ }^{1}$ Complications from unsafe abortion are believed to account for the largest proportion of hospital admissions for gynaecological services in developing countries and to mention the cost it imparts to the health system of country. It is said that care of patient hospitalized as a result of unsafe abortion can be more

Correspondence: Dr. Punya Paudel, Maternity Hospital, Thapathali, Kathmandu, Nepal. Email: punya.dr@gmail.com, Phone: 9851107356. 
than 2500 times the daily per capita health budget. The major cause of induced abortion has been unintended pregnancy and unmet demand of family planning. Thus, it is postulated that about 100,000 maternal deaths can be prevented each year ${ }^{1}$ if the unmet need for family planning with the safe motherhood programs are met accordingly. Thus, it is of priority to understand the pattern of fertility and health seeking behavior by the women.

The contribution of unsafe abortions to maternal deaths and morbidity was acknowledged by key stakeholders in Nepal in the mid-1990s, which led to the advocacy for abortion law in 2002. ${ }^{3}$ It was finally approved by Department of Health Services in 2009 after completing parliamentary formalities and introduced in hospitals and a few primary health centers (PHCs). ${ }^{4}$ But the first government abortion services officially began long before, in March 2004 at the Maternity Hospital in Kathmandu; and expanded gradually to other public and private hospitals and private clinics in the coming years. Literature suggests that there has been an increasing access to safe abortion services in Nepal preventing the burden of unsafe abortion, and remains a high priority. However few studies in the past found that only $44 \%$ and $66.5 \%$ of women were aware that abortion was legal in Nepal. ${ }^{5,6}$ It has also highlighted for the need of reorientation of abortion services including awareness of abortion legislation in Nepal given by their finding that $89 \%$ of women used unsafe substances from the uncertified sources for abortion. ${ }^{5}$

This study therefore, aims to find out the prevalence and the pattern of abortion among the women who utilize the safe abortion care services at Maternity Hospital, Kathmandu. It also aims to provide a framework to target various health promotion programs including safe-motherhood and reproductive health; such that the future interventions to avoid the unintended pregnancy and unsafe abortion can be implemented accordingly.

\section{METHODS}

A cross-sectional study was conducted with a collection of data from hospital records of Paropakar Maternity hospital, Thapathali, Kathmandu, Nepal. Social and demographic information of all the women seeking induced abortions from January 2011 to December 2012 were included, while the missing files and information were excluded.

An ethical clearance was taken from the hospital. The data were analyzed using SPSS version 19 for Windows.

\section{RESULTS}

The total patients served during the year 2011 and 2012; including new cases and follow-ups was 147,470 and 140,051 respectively. There were total 4830 patients who underwent induced abortion in this period at the Maternity Hospital with total of 2591 women in 2011 and 2239 women in 2012 respectively. The sociodemographic characteristics of the study participants are given at (Table 1 ).

Of them majority of women between 25 to 29 years, followed by $20-24$ received the abortion care. The mean age was 27. Among them, 92.3\% were from the Kathmandu valley, and rest outside from the valley (Table 1).

\begin{tabular}{|ll|}
\hline $\begin{array}{l}\text { Table 1. Percentage distribution of variables in the } \\
\text { sample }(\mathbf{N}=\mathbf{4 8 3 0}) .\end{array}$ \\
\hline Age & $\mathbf{N}(\%)$ \\
10 to 14 & $14(0.29)$ \\
15 to 19 & $229(4.74)$ \\
20 to 24 & $1263(26.15)$ \\
25 to 29 & $1490(30.85)$ \\
30 to 34 & $1081(22.38)$ \\
35 to 39 & $539(11.16)$ \\
40 to 44 & $188(3.89)$ \\
45 to 49 & $21(0.43)$ \\
50 and more & $5(0.10)$ \\
Parity & $\mathbf{N}(\%)$ \\
0 & $576(11.9)$ \\
1 & $1423(29.5)$ \\
2 & $1958(40.5)$ \\
$3+$ & $873(18.1)$ \\
Education level & $\mathbf{N}(\%)$ \\
Illiterate & $1699(35.2)$ \\
Literate (can read and write) & $177(3.6)$ \\
Secondary & $337(7.0)$ \\
Higher Education & $980(20.3)$ \\
& $557(11.5)$ \\
Ethnicity & $1080(22.4)$ \\
& $\mathbf{N}(\%)$ \\
\hline &
\end{tabular}




\begin{tabular}{|ll|} 
Dalit & $245(5.1)$ \\
Disadvantaged Janajaati & $1507(31.2)$ \\
caste) & $10(0.2)$ \\
Religious minorities & $3(0.1)$ \\
Relatively advantage Janajati & $789(16.3)$ \\
Upper caste group & $2259(46.8)$ \\
Others & $17(0.3)$ \\
Residence & \\
Kathmandu Valley & $\mathbf{N}(\%)$ \\
Outside valley & $4457(92.3)$ \\
Choice of Contraception after CAC & $\mathbf{N}(\%)$ \\
Condoms & $433(7.7)$ \\
Pills & $1011(20.9)$ \\
Depoprovera & $1238(26.6)$ \\
Female sterilization & $302(6.3)$ \\
Male sterilization & $18(0.4)$ \\
IUCD & $407(8.8)$ \\
Implant & $343(7.1)$ \\
Not decided & $1032(21.3)$ \\
\hline \hline
\end{tabular}

There were more women belonging to higher caste (Table 1) indicating the majority of women were from Kathmandu and nearby areas. Also majority were more than two parity. More than one-third women (35.2\%) were illiterate who couldn't read and write and only about one-third women actually completed SLC and higher. So education seems to be one of the strong determinants in the cause of unintended pregnancy. Also women of higher caste seem to opt for the abortion more readily compared to the janajatis and other ethnic groups.

\section{Trend of Abortion}

Abortion contributed to about $1.68 \%$ of the total patient served in the hospital that provides both obstetrical and gynecological services.

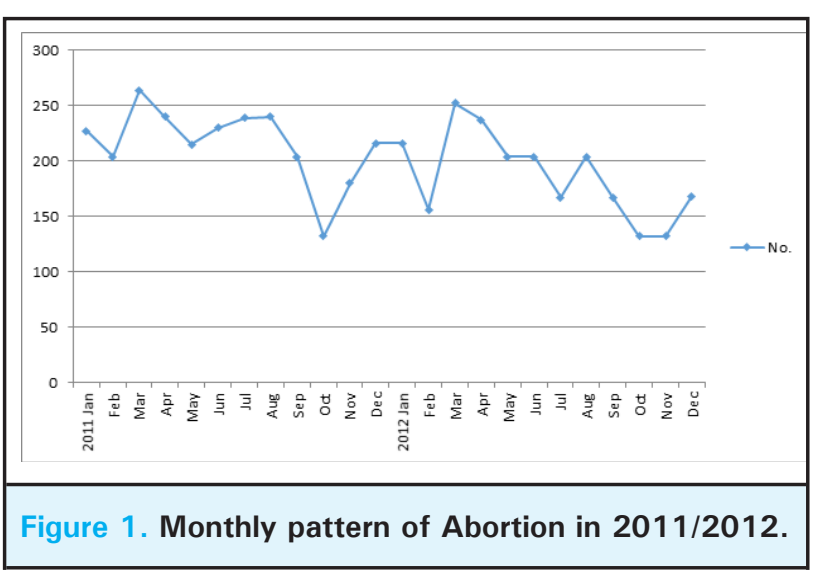

The number of women undergoing abortion was similar in both years; however bimodal peak has been seen in 2011 during the March and August, whilst in 2012, the peak was seen during the March (Figure 1).

Almost $96.6 \%$ of women underwent CAC (Comprehensive Abortion Care) during the first trimester and $3.4 \%$ in the second trimester. Among them majority of the women did not have any complications but incomplete abortion, bleeding and uterine perforation were found respectively in $62(1.3 \%), 17(0.4 \%)$ and $11(0.2 \%)$ of females. Repeat CAC was done in 925 $(19.2 \%)$ of those who had complication of incomplete abortion and bleeding. Total 1238 (26.6\%) chose Depoprovera as the choice of contraception after abortion and 1011 (20.9\%) opted for pills while IUCD, condoms and implants were less preferred choice of contraception. Six percent women who completed family went for sterilization while there was very less number of male sterilizations. Also 1033 (21.3\%) females could not decide their choice of contraception (Table 1).

\section{DISCUSSION}

According to $\mathrm{WHO}$ an estimated 40-50 million abortions occur annually across the globe. This corresponds to approximately 125,000 abortions per day. The risk of dying from an unsafe abortion is around 350 per 100 000 while 68,000 women die yearly due to unsafe abortion. ${ }^{7}$

Every year the number of abortion done in Nepal is also increasing. ${ }^{8}$ There are more than 245 approved sites providing safe abortion services to women across the country. ${ }^{9}$ However, the proper reporting of cases and monitoring of these centers has always been a challenge.

The burden of abortion care in Maternity Hospital has not increased due to the provision of CAC facilities in various districts and rural areas. Of the estimated 1 lakhs of abortion each year done in the country, ${ }^{8}$ there has been about annual average of 2400 abortion in Maternity Hospital. This is the clear indication of the outreach of the CAC service outside the Maternity hospital which is the largest public sector abortion service provider. The safe abortion service has been provided by many public hospitals and health centres, Marie Stopes International, Family Planning Association and other NGO. The expansion of safe abortion care across Nepal is one of several strategies that helped Nepal nearly halve its maternal mortality ratio in the last decade, reducing the number of women who die from pregnancy-related complications from 539 to 281 per 100,000 live births in 2006 and further 281 to 229 per 100,000 live births in 2009 (based one eight districts 
findings).${ }^{10}$ Every year the number of women served increased from 2004 to 2011 with total of almost 5 lakhs Nepalese women served in this period. ${ }^{8}$ The overall post-abortion complication has been low and efforts of the government and involved stakeholders have been appreciable.

Despite increase in the number of women receiving safe abortion care, ${ }^{4}$ the socio-demographic profile of the abortion clients in Nepal has remained similar over the years, which has been evidenced in other past studies as well. ${ }^{6,11-13}$ More women are seeking for safe abortion which is a positive awareness of service availability preventing the burden of unsafe abortion and significantly reducing the burden of patients flow to the capital and major cities. But as the study shows, very less proportion of women from disadvantaged group utilized the abortion services. This lower utilization of such services might be contributed to the access barrier to the safe abortion services, as WHO determined access barrier as lack of information, cost crises, social exclusion and lack of social support grounded in social determinants of health. Thus, there is still unmet need to be fulfilled to reach out the underprivileged groups and minorities group. Hence, continuous education, re-enforcement and reorientation of health system addressing the needs of the socially disadvantaged group is of paramount importance to decrease the burden of unsafe abortion, decrease maternal mortality and morbidity and thereby ensure better family planning to prevent the global epidemic of unwanted pregnancy.

Present study also indirectly supports there is increased utilization of abortion care. Our study from the largest abortion clinic is just a glimpse; there are many abortion clinics that provide safe abortion care out of Kathmandu valley. Also, many abortions go unnoticed and unrecorded in many private clinics. Thus the limitation of our study is that if has data from only one institution, and doesn't address the causal association of the demographic parameters and the safe abortion care services utilization explained by the fallacy of the cross sectional study design. Beside this we cannot actually confer the pattern and the data to infer the actual abortion rate. Therefore, we would like to highlight the importance of the further studies with longitudinal study design which can establish the association between the various demographic parameters and the CAC service utilization in the country, such that intervention can be implicated to address the access barrier to CAC utilization. The provision of the CAC services throughout the country, but we still see lag in reducing the maternal mortality rate, thus, we focus to reorient the research towards the women perceptions about this issue with help of qualitative study design. Also, given by the complexity of the pregnancy, unwanted pregnancy, reproductive health, abortion and unsafe abortion, maternal and child health care, it is necessary to understand the perceived meaning and perception related to such issues in order to recognize the need and act accordingly in terms of services and education.

\section{CONCLUSION}

With this article, we would like to forward that inclusion of mother and child health care in all policies should be a priority to achieve the Millennium declaration and overall improve the maternal and child health state of the country. Safe abortion care and motherhood does matter and goes beyond how a country defines what is legal and what is not. At the moment, we need to address the accessibility and availability to the safe abortion care services along with other safe motherhood programs guaranteeing access to abortion and postabortion care. Thus, creating and strengthening healthy health policies to decrease the widening gap in life expectancy of women among the women across the globe attributing to various social determinants of health is need for the present scenario to ensure the equity of maternal health. Women education regarding contraception is a key to ensure effectiveness of family planning services and avoid repeated abortions or unwanted pregnancy in the future.

\section{REFERENCES}

1. World Health Organization. Dept. of Reproductive Health and Research. Make every mother and child count : World Health Day, 7 April 2005 : a toolkit for organizers of activities. Geneva: World Health Organization; 2005. 22 p. p.

2. World Health Organization 2010: Equity, social determinants and public health programmes [Internet]. 2010. Available from: http://whqlibdoc.who.int/ publications/2010/9789241563970_eng.pdf.

3. Shakya G, Kishore S, Bird C, Barak J. Abortion law reform in
Nepal: women's right to life and health. Reproductive health matters. 2004;12(24 Suppl):75-84.

4. KCN, Basnett I, Sharma SK, Bhusal CL, Parajuli RR, Andersen KL. Increasing access to safe abortion services through auxiliary nurse midwives trained as skilled birth attendants. Kathmandu University medical journal. 2011;9(36):260-6.

5. Rocca CH, Puri M, Dulal B, Bajracharya L, Harper CC, 
Blum M, et al. Unsafe abortion after legalisation in Nepal: a cross-sectional study of women presenting to hospitals. BJOG : an international journal of obstetrics and gynaecology. 2013;120(9):1075-83.

6. Tuladhar H, Risal A. Level of awareness about legalization of abortion in Nepal: a study at Nepal Medical College Teaching Hospital. Nepal Medical College journal : NMCJ. 2010;12(2):76-80.

7. World Health Organization., UNICEF., World Bank., United Nations Population Fund. Maternal mortality in 2005 : estimates developed by WHO, UNICEF, UNFPA, and The World Bank. Geneva: World Health Organization; 2007. 40 p. p.

8. Samandari G, Wolf M, Basnett I, Hyman A, Andersen K. Implementation of legal abortion in Nepal: a model for rapid scale-up of high-quality care. Reproductive health. 2012;9:7.

9. Khanal V, Joshi C, Neupane D, Karkee R. Practices and perceptions on contraception acceptance among clients availing safe abortion services in Nepal. Kathmandu University medical journal. 2011;9(35):179-84.

10. Ipas Nepal. A better place for women: Abortion care in Nepal a decade after law reform [Internet]. 2012. Available from: http://www.ipas.org/en/Resources/ Ipas\%20Publications / A-better-place-for-women--Abortioncare-in-Nepal-a-decade-after-law-reform.aspx.

11. Thapa S, Neupana S, Basnett I, Ramnarayan K, Read E. Women having abortion in urban Nepal: 2005 and 2010 compared. Kathmandu University medical journal. 2012;10(39):8-13.

12. Henderson JT, Puri M, Blum M, Harper CC, Rana A, Gurung G, et al. Effects of abortion legalization in Nepal, 2001-2010. PloS one. 2013;8(5):e64775.

13. Moller A, Ofverstedt S, Siwe K. Proud, not yet satisfied: the experiences of abortion service providers in the Kathmandu Valley, Nepal. Sexual \& reproductive healthcare : official journal of the Swedish Association of Midwives. 2012;3(4):135-40. 